\title{
Primary management of post-burn contracture neck with tracheostomy: A surgeon and an anaesthetist's perspective
}

Sir,

A 42-year-old female with severe post-burn contracture neck (8-year-old), [Figures 1 and 2] with restricted mouth opening (1 finger), Mallampati 4 , maxillo-pharyngeal angle about $90^{\circ}$ treated initially at a primary health centre, came to our setup for the surgical management of the contracture. After the patient was explained about the unavailability

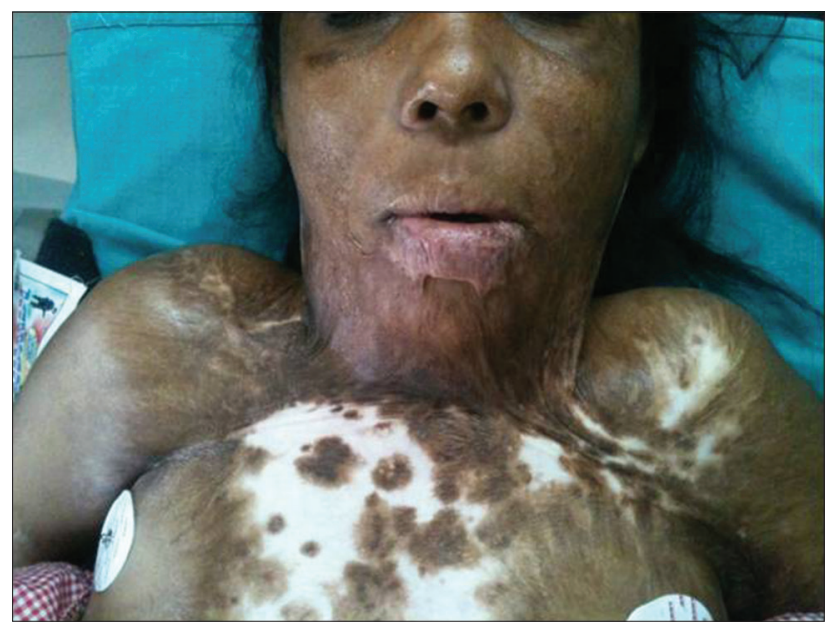

Figure 1: Pre-operative photograph of the patient showing severe post-burn contracture of the neck 


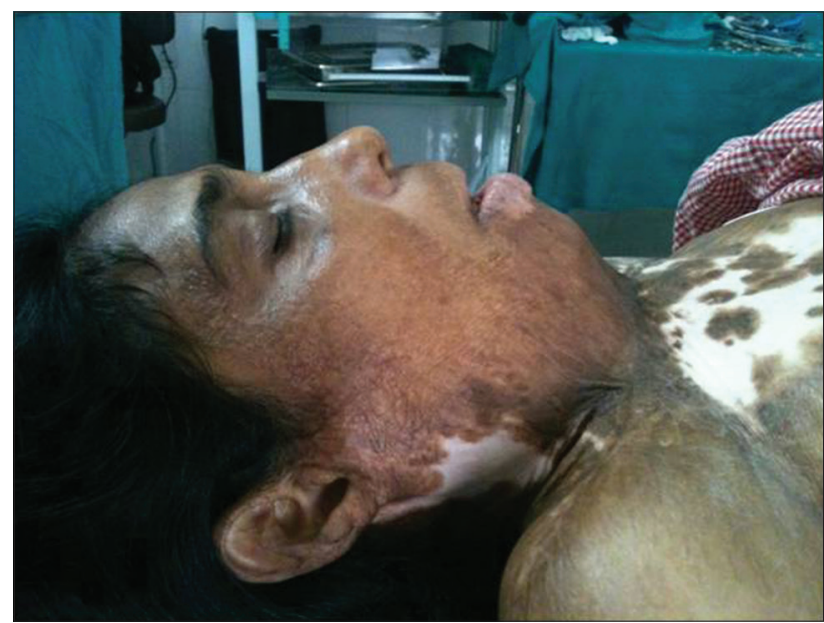

Figure 2: Side profile of the patient pre-operatively showing the degree of sternomental contracture

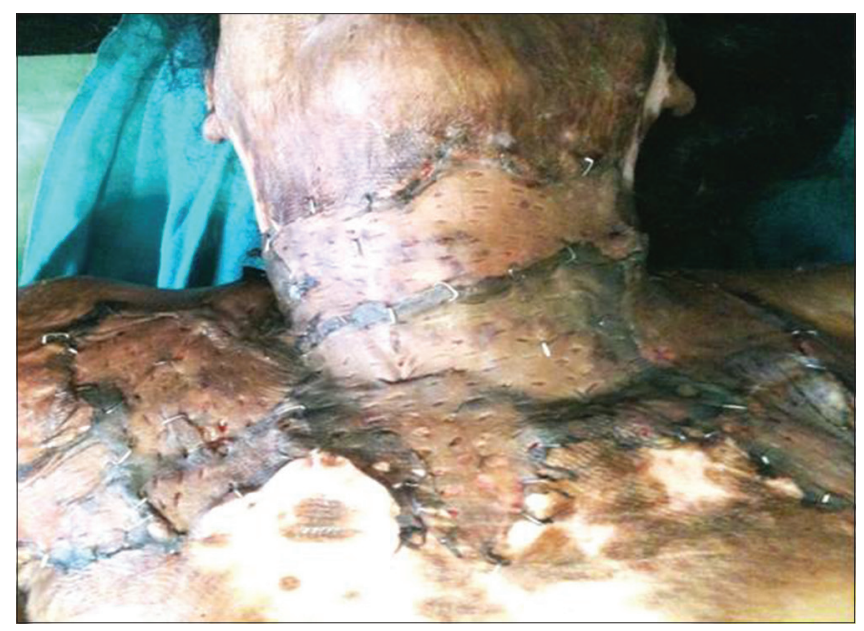

Figure 4: Post-operative photograph of the patient with skin graft after release

of fibre-optic bronchoscopy, ${ }^{[1]}$ she was optimised and taken up for surgery. Consent for emergency tracheostomy was taken as a protocol.

After two unsuccessful attempts of intubation following the release of neck bands under local anaesthesia and eventual sedation with injection midazolam and injection propofol and check ventilation, the patient was considered for tracheostomy [Figures 3 and 4]. After administering vecuronium, the tracheostomy established the airway. Then, the contracture was further released. At this point of time, a reattempt of intubation with an endotracheal tube attempted over a stylet, simultaneously withdrawing the tracheostomy tube, was successful. The Bjork's flap was closed after achieving haemostasis. Strap muscles were also apposed with sutures. Skin grafts harvested from the thigh were used to resurface the raw areas and secured [Figure 5].

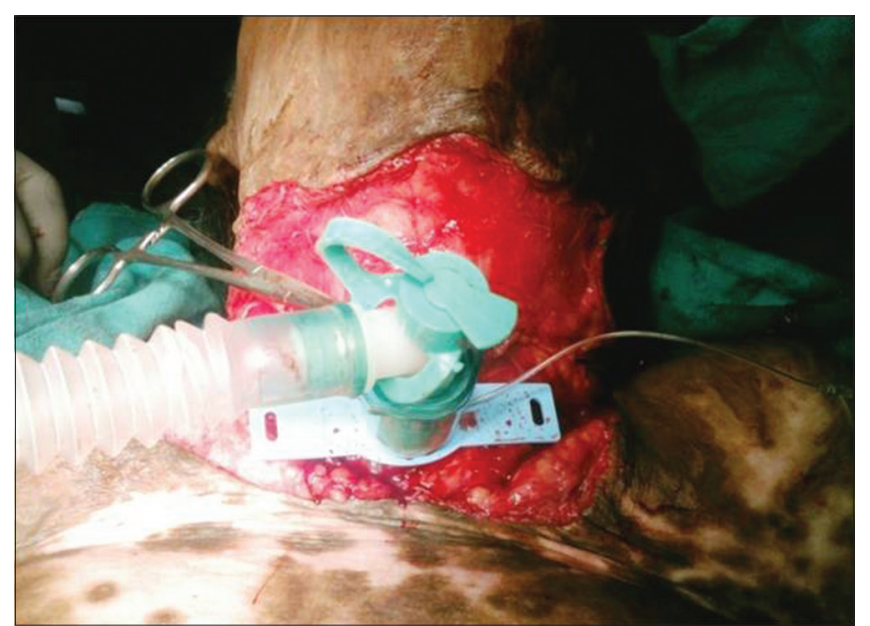

Figure 3: Tracheostomy in situ as an interim procedure to allow further release of the contracture and correct the oropharyngolaryngeal axis

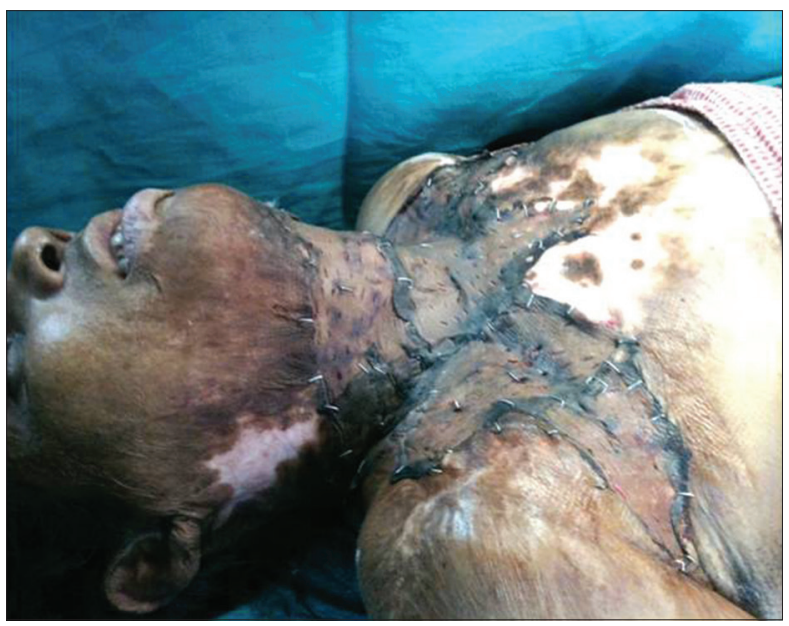

Figure 5: Post-operative photograph of the patient showing the degree of release and the excellent take of the graft

The post-operative period was uneventful and the graft take was satisfactory.

Literature reveals numerous methods of handling a difficult airway using C-Trach, intubating Laryngeal mask airway-(LMA), fibreoptic bronchoscope and AMBU LMA. ${ }^{[2]}$ If awake intubation fails, the first step would be to release the contracture bands under injection ketamine $e^{[3]}$ and local anaesthesia. But then, that would mean that the patient would be under spontaneous ventilation and compromise in the quality of surgery. Furthermore, the use of long-acting muscle relaxants would be contraindicated at this stage.

Tracheostomy still has been quoted at the end of the algorithm for management of these airways. The fear of surgical emphysema, bleeding eventually 
obstructing the airway, oedema and leaks has made tracheostomy unpopular among surgeons as well as anaesthetists for such cases. However, in our cases, scenario tracheostomy was fortunately advantageous as it enabled (1) the use of long-acting muscle relaxants and (2) correcting the tracheobronchial axis by allowing further release of the extensive contracture bands and eventual introduction of endotracheal tube eventually. The main part of emphasis of the article is the ultimate successful closure of the tracheostomy and successful graft resurfacing and uptake contrary to the traditional fear of graft loss due to contamination. The authors would like to recommend the use of indirect laryngoscope $\mathrm{e}^{[4]}$ as one of the pre-anaesthetic examinations for such patients to anticipate such airway difficulties.

\section{Financial support and sponsorship}

Nil.

\section{Conflicts of interest}

There are no conflicts of interest.

\section{Madhubari Vathulya, Seema Shukla, Navin Shukla \\ Department of Surgery, Subharti Hospital, Dehradun, Uttarakhand, India}

Address for correspondence: Dr. Madhubari Vathulya, 401, Anandlegacy Apartments, Shastri Nagar, Haridwar Road, Dehradun - 248 001, Uttarakhand, India. E-mail: madhubarivathulya079@gmail.com
This is an open access article distributed under the terms of the Creative Commons Attribution-NonCommercial-ShareAlike 3.0 License, which allows others to remix, tweak, and build upon the work non-commercially, as long as the author is credited and the new creations are licensed under the identical terms.

\begin{tabular}{|l|l|}
\hline \multicolumn{2}{|c|}{ Access this article online } \\
\hline Quick Response Code: & Website: \\
\hline
\end{tabular}

How to cite this article: Vathulya M, Shukla S, Shukla N. Primary management of post-burn contracture neck with tracheostomy: A surgeon and an anaesthetist's perspective. Indian J Plast Surg 2017;50:117-9.

๑ 2017 Indian Journal of Plastic Surgery | Published by Wolters Kluwer - Medknow

\section{REFERENCES}

1. Han TH, Teissler H, Han RJ, Gaines JD, Nguyen TQ. Managing difficult airway in patients with post-burn mentosternal and circumoral scar contractures. Int J Burns Trauma 2012;2:80-5.

2. Mathur R, Jain PK, Chakotiya PS, Rathore P. Anaesthetic and airway management of a post-burn contracture neck patient with microstomia and distorted nasal anatomy. Indian J Anaesth 2014;58:210-3.

3. Al-Zacko SM, Al-Kazzaz DA. Initial release of severe post-burn contracture scar of the neck for intubation under ketamine. Ann Burns Fire Disasters 2009;22:196-9.

4. Law JA, Broemling N, Cooper RM, Drolet P, Duggan LV, Griesdale DE, et al. The difficult airway with recommendations for management - Part 1 - Difficult tracheal intubation encountered in an unconscious/induced patient. Can J Anaesth 2013;60:1089-118. 